\title{
Entre Dos Tierras aúna academia y sociedad para dar a conocer el patrimonio arqueológico en los Montes de Toledo
}

\begin{abstract}
Entre Dos Tierras nace con la voluntad de divulgar el patrimonio arqueológico de los Montes de Toledo y concienciar a la población de la importancia que tiene su protección y conservación. Además, pretende responder a una serie de preguntas en torno al conocimiento de la Edad del Bronce en el interior peninsular. Para ello, se centra en el análisis del poblamiento y el arte esquemático en la comarca natural de Los Montes de Toledo y sus territorios limítrofes, usando como herramienta la excavación de alguno de los yacimientos más representativos. El primero seleccionado ha sido el Montón de Trigo, localizado en la sierra de Los Yébenes (Toledo).
\end{abstract}

Arturo Ruiz Taboada | Dpto. de Prehistoria, Historia Antigua y Arqueología, Universidad Complutense de Madrid

URL de la contribución <http://www.iaph.es/revistaph/index.php/revistaph/article/view/5026>

Entre Dos Tierras es el nombre del proyecto que combina investigación y difusión con el objetivo de dar a conocer el inmenso patrimonio arqueológico que atesoran los Montes de Toledo y resolver cuestiones que tienen que ver con la cronología de los asentamientos, el medio natural y la subsistencia de hace 3.500 años. Además, pretende averiguar el papel que, en su momento, ejercieron los Montes de Toledo en la configuración del poblamiento de la Edad del Bronce en la submeseta sur.

El objetivo es reactivar los estudios de la Edad del Bronce en la comarca de los Montes de Toledo, que actualmente comprende las provincias de Toledo y Ciudad Real, y ponerla en relación con los dos territorios que la limitan: la cuenca media del Tajo y La Mancha. Para ello, el proyecto contempla la excavación de alguno de los poblados localizados en las cimas de la Sierra de Los Yébenes, conjunto de estribaciones montañosas que marcan el límite noroccidental con La Mancha. Por último, se pretende establecer una relación entre el poblamiento prehistórico de los montes y la amplia muestra de arte esquemático existente.

\section{Los principales fines}

La localización de la mayoría de los yacimientos en lugares inaccesibles ha dificultado tanto su estudio científico como su protección frente a la acción indiscriminada de

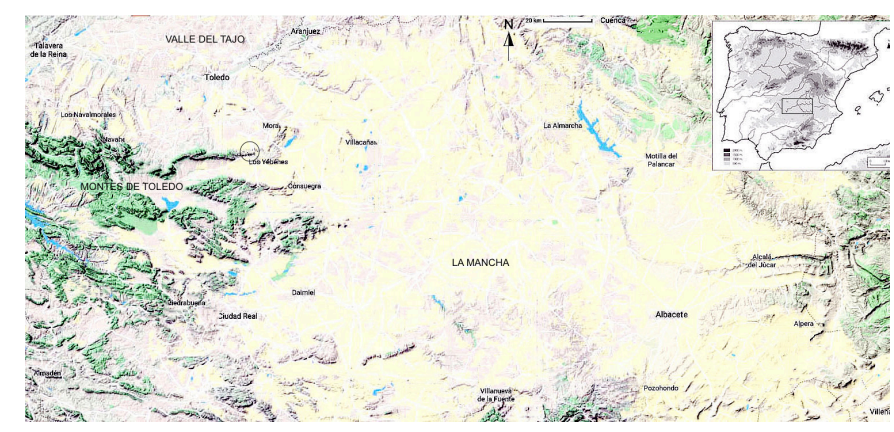

Los Montes de Toledo y el Montón de Trigo en el contexto de La Mancha y la Cuenca Media del Tajo | mapa Iberpix. Centro Nacional de Información Geográfica e Instituto Geográfico Nacional, modificado

aficionados a la arqueología que, década tras década, han ido saqueando sus depósitos.

El proyecto surge no sólo con el objetivo de plantear una investigación de largo recorrido en la zona, sino con vocación didáctica, al considerar que el conocimiento es clave a la hora de conservar y valorar el patrimonio cultural.

La intervención en diferentes yacimientos requiere de infraestructuras, medios y personal especializado. Los medios los aportan tanto el Ayuntamiento de Los Yébenes como la Diputación Provincial de Toledo. El proyecto, además de la difusión de los resultados, pretende formar futuros arqueólogos y ser la plataforma para desarrollar trabajos de investigación complemen- 
tarios y de máster. Para ello se cuenta con estudiantes universitarios del grado de arqueología y con yebenosos, interesados en conocer su patrimonio arqueológico. El punto de partida fue la firma por parte del Ayuntamiento de Los Yébenes de sendos convenios de práctica con el Departamento de Prehistoria, Historia Antigua y Arqueología de la Universidad Complutense de Madrid y con el Centro de Estudios Internacionales de la Fundación Ortega Marañón de Toledo.

Desde un punto de vista científico, el proyecto cuenta con la colaboración de diversos laboratorios, centros

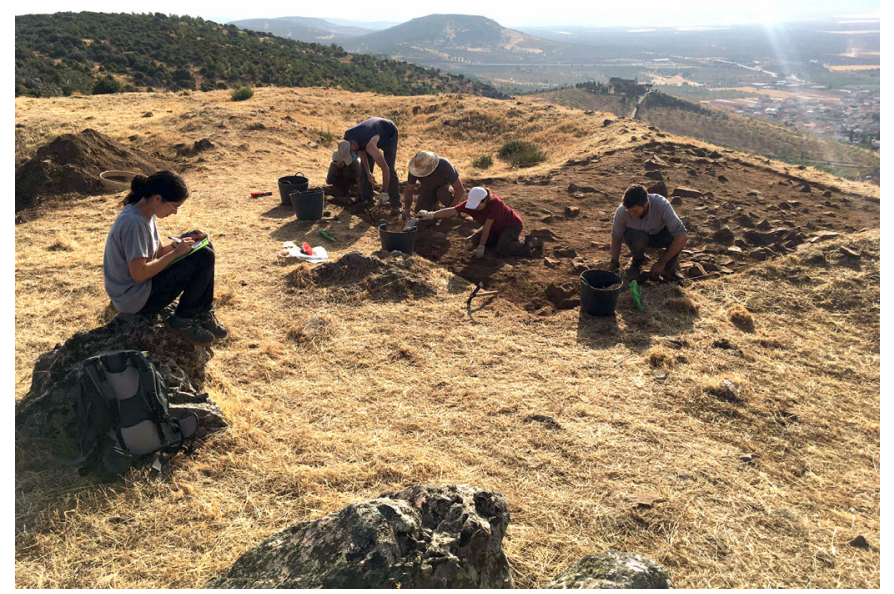

Primera campaña de excavación en la que han participad alumnos de arqueología de la Universidad Complutense y voluntarios locales | foto Arturo Ruiz Taboada

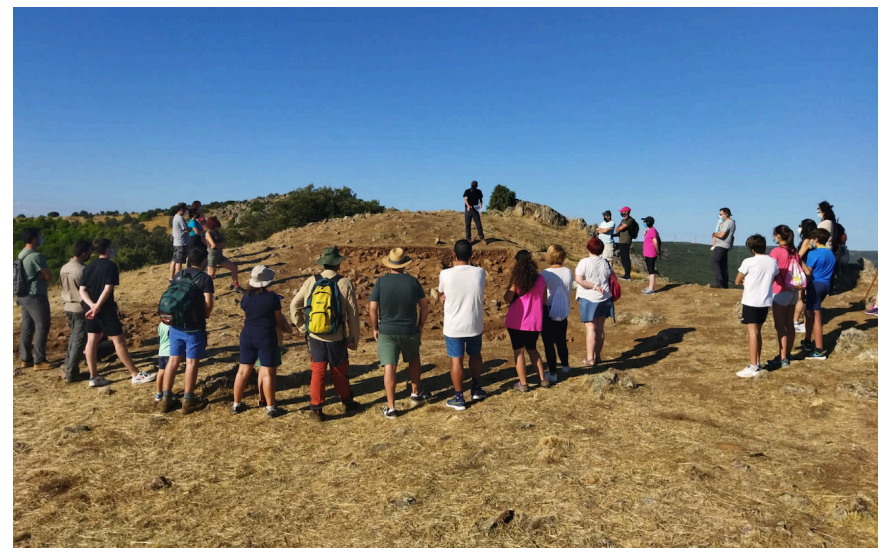

Jornada de puertas abiertas del yacimiento de Montón de Trigo celebrada el sábado 28 de agosto de 2021 | foto José María Martín e instituciones. Entre ellos el CAl (Centro de Apoyo a la Investigación) de la Universidad Complutense, la Universidad de Groningen (Países Bajos), el Departamento de Petrología y Geoquímica de la Universidad Complutense de Madrid y los departamentos de Metalurgia y Medio Ambiente del Consejo Superior de Investigaciones Científicas (Madrid).

\section{La primera campaña de excavación}

El proyecto se inicia en agosto de 2021 con la primera campaña de excavación del yacimiento del Montón de Trigo, propiedad del ayuntamiento de Los Yébenes.

El poblado se localiza en lo alto de un crestón de cuarcita que domina un extenso territorio con una superficie de $1.400 \mathrm{~m}^{2}$. El objetivo de la excavación del Montón de Trigo es conocer y documentar tanto la distribución interna del poblado como su cronología y, a medio plazo, comparar los resultados con otros yacimientos de similares características en la comarca. El carácter de frontera natural de los Montes de Toledo, entre La Mancha y la cuenca Media del Tajo, es clave para comprender el origen y desarrollo de la Edad del Bronce en las tierras del interior peninsular.

Además del propósito científico, durante las tareas de excavación se organizaron sendas jornadas de puertas abiertas, para que los vecinos de Los Yébenes conocieran de primera mano los trabajos que se estaban desarrollando en el yacimiento. Estas jornadas tuvieron amplia repercusión en los medios de comunicación a nivel local y regional. Por su parte, el día a día del proyecto y el trabajo de laboratorio se puede seguir a través de perfiles en Instagram (@proyectoentre2tierras) y Facebook (Proyecto Arqueológico "Entre Dos Tierras").

En los últimos días de la campaña contamos también con la presencia del SEPRONA, responsable de velar por la conservación del patrimonio arqueológico y natural. En la visita al yacimiento coincidimos en la importancia de concienciar a la población sobre la protección y el cuidado de nuestro patrimonio arqueológico. Como actividad complementaria, el Ayuntamiento de Los Yébenes viene programando diversas actividades en el municipio destinadas a concienciar a los más 


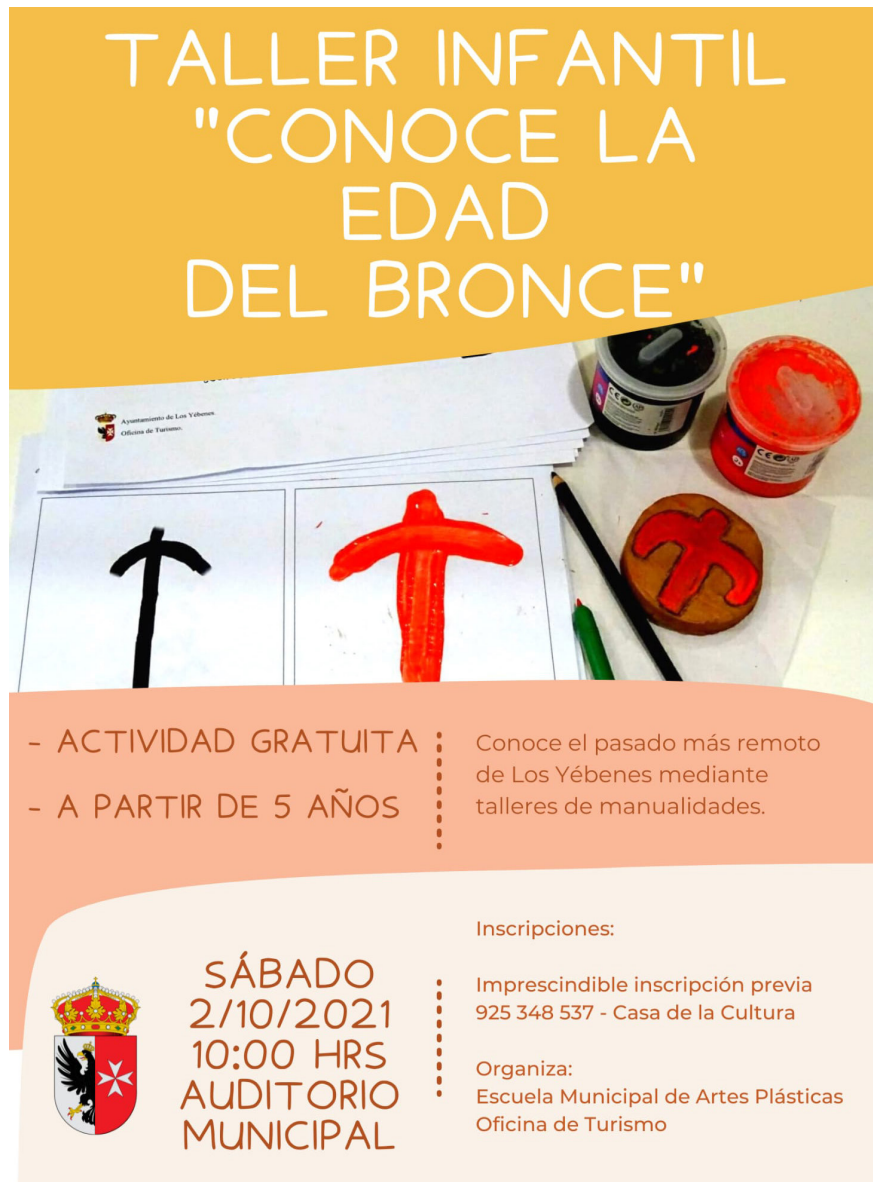

Taller organizado por Félix Antonio Jaime, Oficina de Turismo del Ayuntamiento de Los Yébenes

pequeños sobre la importancia de conocer su patrimonio arqueológico.

\section{Conclusión}

El proyecto Entre Dos Tierras aúna academia y sociedad con la misión de dar a conocer un patrimonio arqueológico poco conocido y en peligro. Para cumplir con este objetivo, la implicación tanto de las administraciones públicas como de la sociedad en la conservación de los yacimientos son clave. En este sentido, nuestra constitución en su artículo 46 lo deja claro: "Los poderes públicos garantizarán la conservación y promoverán el enriquecimiento del patrimonio histórico, cultural y artístico de los pueblos de España, cualquiera que sea su régimen jurídico y su titularidad. La ley penal sancionará los delitos contra este patrimonio". Los años trans- curridos desde esta declaración y las diferentes leyes en vigor en materia de patrimonio han puesto de manifiesto que para que realmente sean efectivas, se debe concienciar a la sociedad de la importancia de valorar y respetar lo que es de todos.

La excavación del Montón de Trigo y de otros yacimientos similares va a permitir dar a conocer un patrimonio olvidado y en constante deterioro. El análisis en curso de los datos obtenidos posibilitará establecer tanto las líneas de investigación futuras como el diseño de un plan de conservación y difusión de este tipo de espacios protegidos. 